\title{
Mature cystic teratoma of the uterus presenting as an
}

\section{endometrial polyp in a patient with a history of ovarian mature cystic teratoma with gliomatosis peritonei and ovarian} endometriosis: a case report

\author{
Y.A. Kim $^{1, *}$ \\ ${ }^{1}$ Department of Obstetrics and Gynecology, Ilsan Paik Hospital, Inje University, Goyang (Republic of Korea)
}

\begin{abstract}
Summary
Teratomas of the uterus are rare neoplasms and are usually polypous lesions that present clinically as abnormal uterine bleeding. Gliomatosis peritonei (GP) is characterized by peritoneal implants of non-neuronal glial tissue and is a rarely-encountered complication of ovarian teratomas. To the best of our knowledge, mature cystic teratoma of the uterus as well as ovarian teratoma with GP and ovarian endometriosis are rare phenomena. Here, we report a case of mature cystic teratoma of the uterus presenting as an endometrial polyp in a patient with a history of ovarian teratoma with GP and ovarian endometriosis.
\end{abstract}

Key words: Mature cystic teratomas of uterus; Ovarian teratoma; Gliomatosis peritonei; Endometriosis.

\section{Introduction}

Mature cystic teratomas are cystic tumors comprising well-differentiated tissue derived from at least two of the three germ cell layers $[1,2]$. Mature cystic teratomas typically occur in the ovaries. However, they can be extragonadal, although they are rarely located in the uterus [3]. Here, we report a case of mature cystic teratoma of the uterus presenting as an endometrial polyp in a patient with a history of ovarian teratoma with gliomatosis peritonei (GP) and ovarian endometriosis. To our knowledge, this is the first reported case and a clinically important example.

\section{Case Report}

A 24-year-old nulliparous woman presented with an endometrial mass with vaginal bleeding. Previous gynecologic history included the diagnosis of ovarian teratoma with GP at 19 years old and pelvic endometriosis with peritoneal gliomatosis at 21 years old. The patient had regular menstruation after the age of 13 . Her history includes a physical examination at the time of the first operation, in which normal external genitalia and a black-colored nevus on the left leg were noted. The subject visited the emergency room at a local hospital with sudden onset of pain and underwent the first operation three days later. A large $20 \times$ $13 \times 28 \mathrm{~cm}$ ovarian tumor was discovered via computed tomography $(\mathrm{CT})$, with a CA125 of $115.8 \mathrm{U} / \mathrm{mL}$ (reference range: $<35 \mathrm{U} / \mathrm{mL}$ ). At the time of surgery, a cyst filled the pelvis and abdomen, with peritoneal adhesions and a $5 \mathrm{~cm}$ subserosal-typed myoma on the anterior wall of the uterus. The ovarian lesion was nodular and contained necrotic material and bony tissue with hemorrhage. Further, there were nodular-shaped fragile tissues on the surface and in the right peritoneum and cul-de-sac area (Figure 1). A glial cell tumor was suspected after examining the frozen biopsy, after which ablation via an argon laser was performed. CA125 levels dropped to $20.5 \mathrm{U} / \mathrm{mL}$ after surgery.

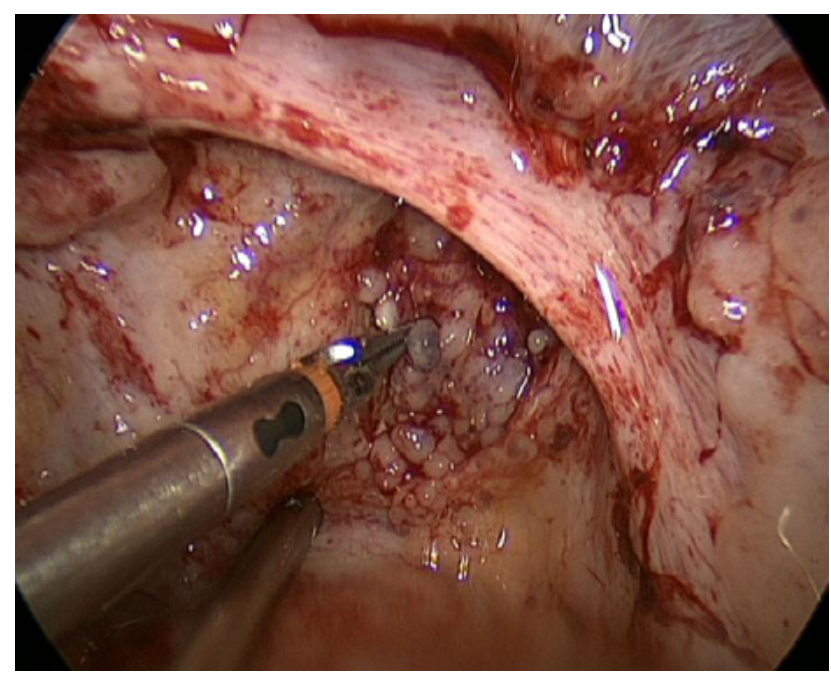

Figure 1. - Gliomatosis peritonei; nodular-shaped fragile tissue on right peritoneum and cul-de-sac area on right pelvic wall. 

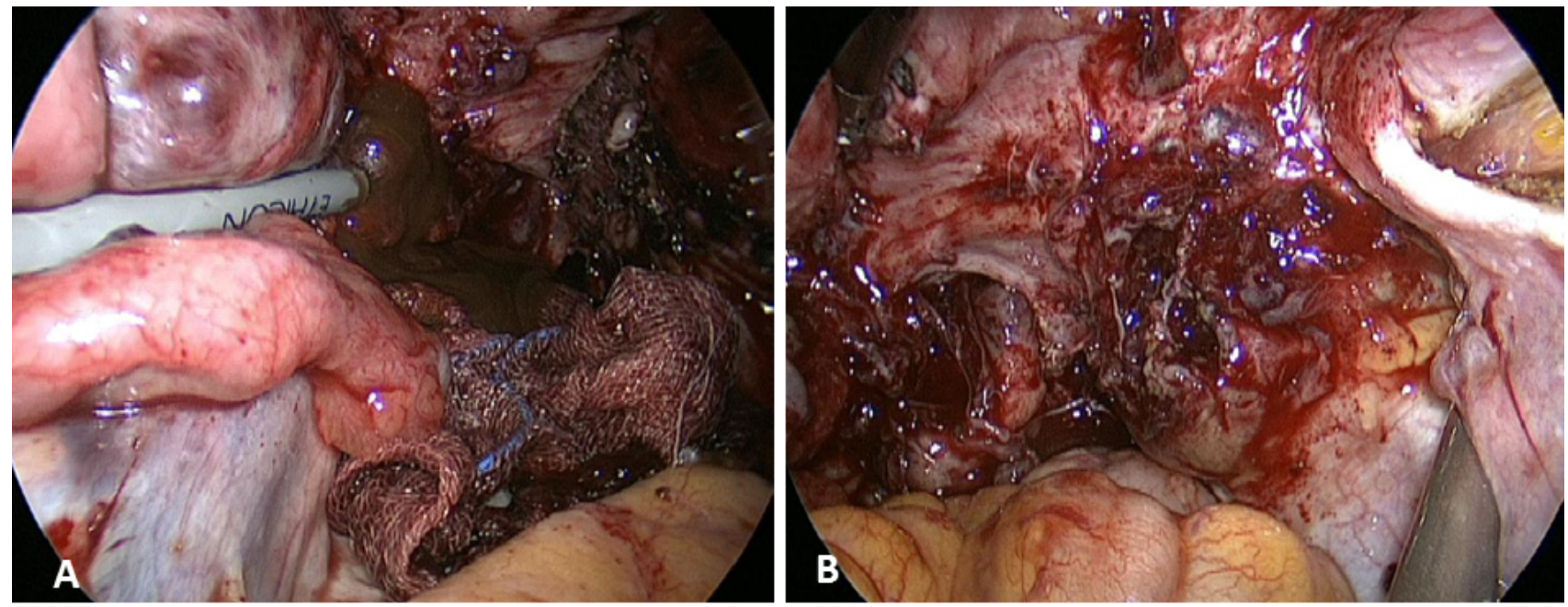

Figure 2. - (A) Left ovarian cyst with chocolate-colored fluid, (B) pelvic mass with a nodular shape on the right pelvic wall.

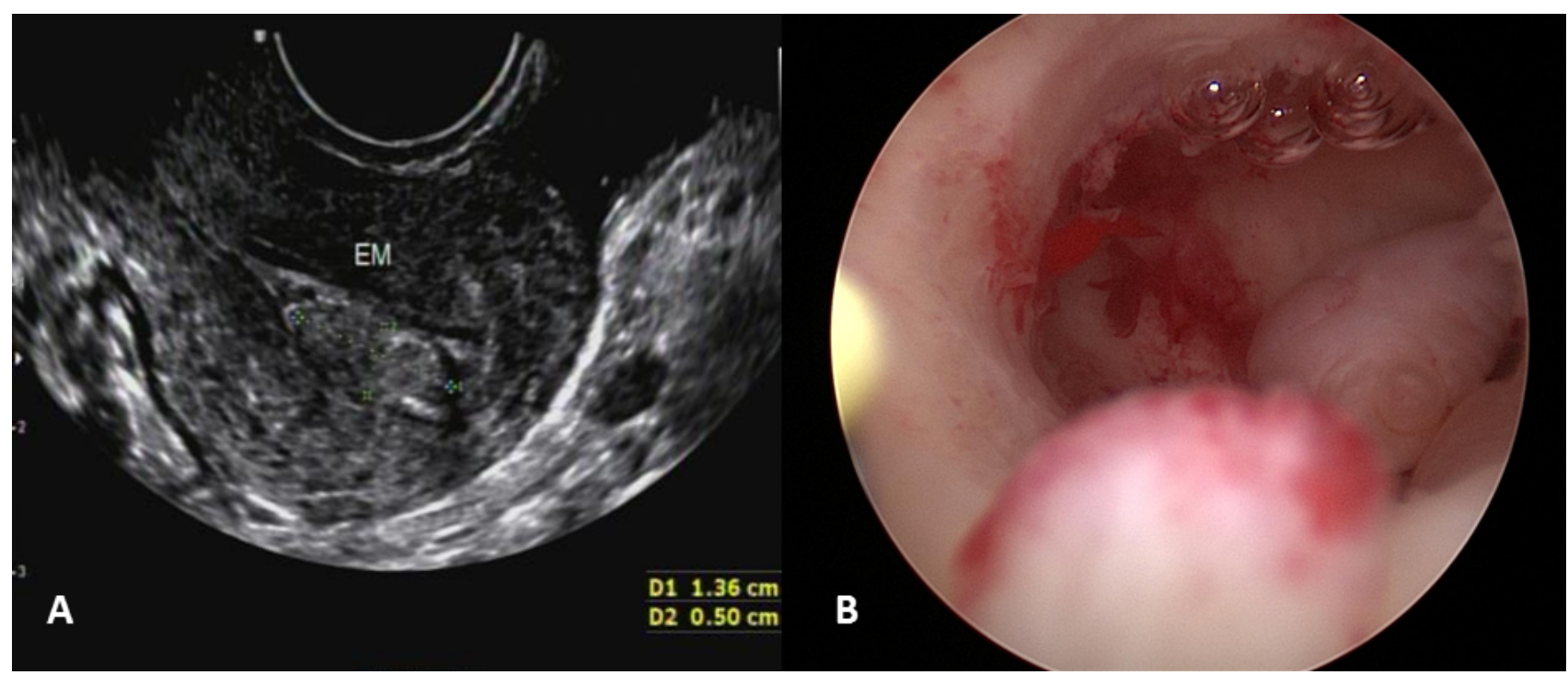

Figure 3. - (A) Ultrasound images of endometrial mass, (B) hysteroscopic finding of polypoid mass.

One year later, a $1.36 \times 1.06 \mathrm{~cm}$ echogenic mass was discovered in the right pelvic area via sonographic examination. One year and eight months later, a $1.72 \times 1.37$ $\mathrm{cm}$ semisolid cyst in the left ovary, $1.16 \times 0.9 \mathrm{~cm}$ mass in the right pelvic side, and $0.51 \times 0.28 \mathrm{~cm}$ echogenic mass without blood flow in the endometrium were noted; CA125 was elevated to $60.1 \mathrm{U} / \mathrm{mL}$, indicating a need for laparoscopic surgery. Despite the endometrial mass, no symptoms such as vaginal bleeding were noted; therefore, only laparoscopic surgery was judged necessary considering the patient's virginity. A $3 \mathrm{~cm}$ cystic lesion had adhered to the left pelvic side wall and cul-de-sac region, while a chocolate-colored fluid was observed during adhesiolysis. Widespread peritoneal, grayish-colored, tiny lesions and gray-colored spots were observed on both side walls (Figure 2). The right pelvic mass was removed, including the peritoneal wall. Pathologic results revealed the pelvic mass as GP and peritoneum as endometriosis. The GP was considered benign and follow-up was determined, while the endometriosis was treated with gonadotropin-releasing hormone $(\mathrm{GnRH})$ agonist therapy to prevent recurrence. After 6 injections of GnRH agonist, progestin was administered conservatively to prevent recurrence of endometriosis.

Three years after the second operation, the endometrial mass showing uterine bleeding increased to $1.36 \times 0.5 \mathrm{~cm}$ with blood flow, necessitating hysteroscopy (Figure 3 ). The hysteroscopic finding suggested an endometrial polyp microscopically composed of vascular smooth muscle, benign looking glands, ducts, and cartilage, all of which are mature tissues and consistent with mature cystic teratoma (Figure 4). 


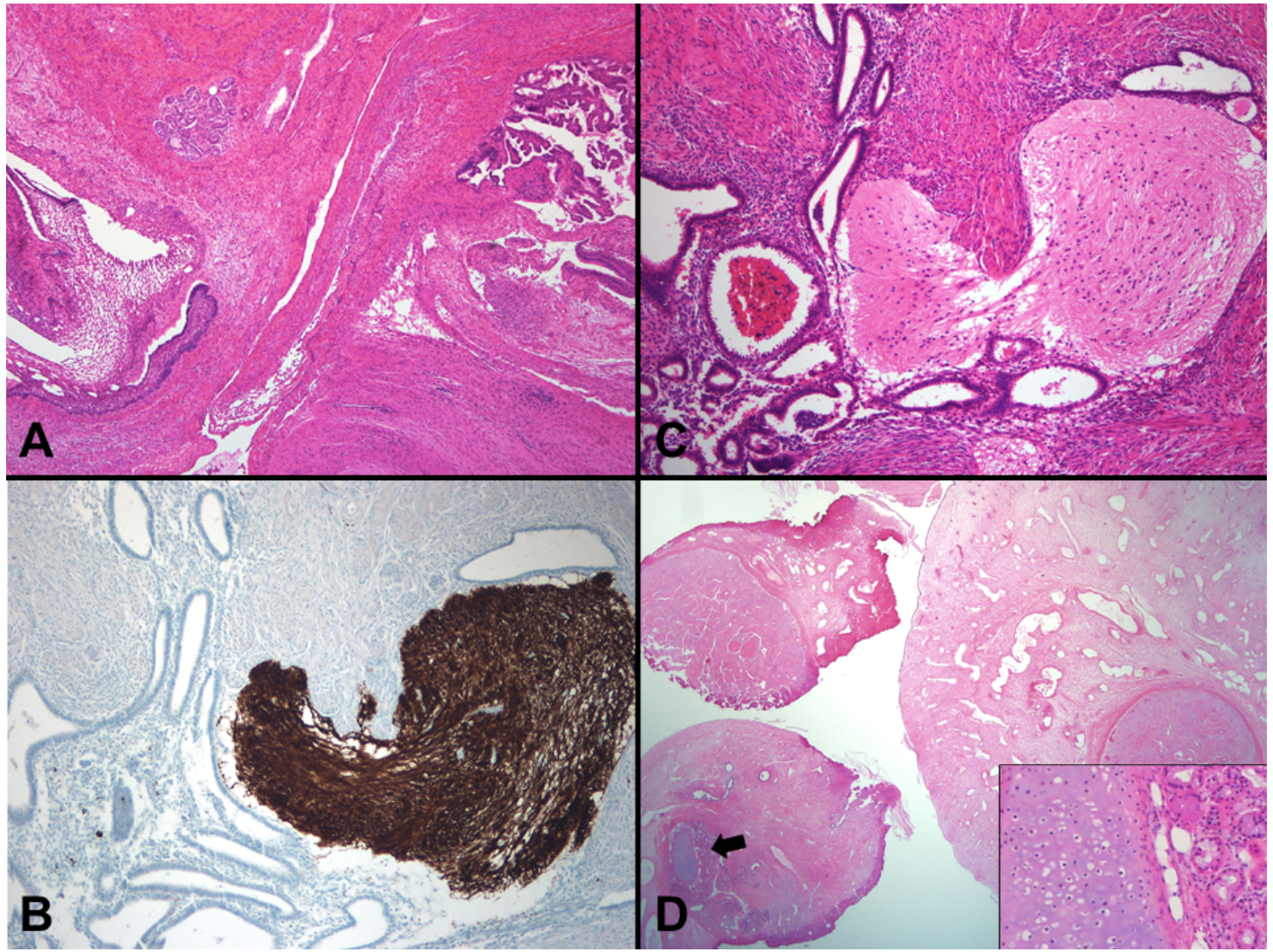

Figure 4. - Pathology images. (A) The ovarian tumor comprises various mature tissues of three germ cell layers, such as squamous epithelium, salivary glands, brain tissue, and choroid plexus $(H \& E, \times 40)$. (B) and $(C)$ Histologically, the peritoneal nodules consist of mature glial tissue, consistent with gliomatosis peritonei. Also, endometrial glands with stroma are scattered and admixed with mature glial tissue, which is highlighted via glial fibrillary acidic protein immunostaining $(\times 200)$. (D) The resected fragments of the endometrial polyp show a round configuration lined by respiratory epithelium on the surface and contain mature smooth muscle, cartilage islands, and salivary glands (arrow and inset) $(\mathrm{H} \& \mathrm{E}, \times 40)$.

\section{Discussion}

Teratomas of the uterus are rare neoplasms. To date, mature or immature teratomas of the uterus have been reported in 10 cases [3-12]. Most reported cases were mature teratomas; however, there are two reports of immature teratomas $[8,12]$ and one report of an immature teratoma coexisting with adenocarcinoma [6]. Teratomas of the uterine corpus are usually polypous lesions that present clinically as abnormal uterine bleeding, consistent with this case.

The origin of endometrial teratoma is not completely understood. It has been suggested that teratomas of the ovaries and the cervix are of parthenogenetic origin from oocytes after completion of the first division [13]. However, uterine teratoma origins have not been established via molecular methods. Wang et al. compared DNA profiles of normal uterine tissue and teratoma tissue using short tandem repeats (STR) analysis and found that teratomas do not originate from the parthenogenetic process [5]. They suggested that the origin of uterine teratomas may be from pluripotential stem cells of the uterus or primordial germ cells before meiosis I.

GP is characterized by peritoneal implants of non- neuronal glial tissue and is a rarely-encountered complication of ovarian teratomas [14-22]. The etiology of GP is largely unknown. Two theories regarding the development of GP have previously been reported, including a relationship to capsular defects of the primary teratoma or dissemination through the vascular lymphatic vessels [21]. Another theory suggests that glial foci are not genetically related to teratomas [22]. Ferguson et al. studied polymorphic microsatellite (MS) loci in two cases to address the origin of GP [23]. They reported that glial implants and normal tissue showed heterozygosity, while the teratoma showed homozygosity at the same MS loci, indicating that glial implants in GP are unrelated to the ovarian teratoma and arise from normal cells such as pluripotent Müllerian stem cells. It is possible that peritoneal stem cells can differentiate into glial cells under the stimulation of some factors secreted from teratomas. Kwan et al. hypothesized that GP could result from pluripotent stem cells in the peritoneal cavity that differentiate along astroglial pathways under the influence of mediators produced by either the teratoma or peritoneal macrophages [24].

To date, eight case reports describe the association be- 
tween GP and endometriosis [16, 18, 25-30]. Six cases were associated with immature teratoma, while the remaining cases involved a mature teratoma as in the present case. The most scientifically supported and widely accepted mechanism of endometriosis is retrograde effluent flow to the pelvic peritoneal cavities through the fallopian tubes during menstruation [25]. Further, tissue degeneration of retrograde menstrual flow plays a central role in inducing inflammatory pain of endometriosis by activating innate immune cells and peripheral nerve endings [31]. In particular, macrophages among the inflammatory process are a major contributor to pro-inflammatory chemotactic cytokines and a major cause of neovascularization [32]. The coelomic metaplasia theory has also been suggested as a possible mechanism, stating that embryonic cells from the Müllerian ducts persist in ectopic locations. Coelomic metaplasia involves the transformation of normal peritoneal tissue to ectopic endometrial tissue, which may be induced by unknown stimuli in other uncommon peritoneal lesions $[33,34]$.

As suggested via the prevailing theories, endometriosis and GP may have a common pathogenesis. As such, a shared origin of both GP and endometriosis from totipotential peritoneal stem cells would explain their occasional coexistence.

In this case study, we observed a mature cystic teratoma causing vaginal bleeding in a patient having ovarian teratoma with GP and endometriosis. To the best of our knowledge, mature cystic teratoma of the uterus as well as ovarian teratoma with GP and ovarian endometriosis are rare phenomena that have not yet been described in the English literature. The findings in this case might lend further support to the theory of a stem cell origin for GP, endometriosis, and uterine teratoma.

\section{Ethics Approval and Consent to Participate}

The study was conducted in accordance with the Declaration of Helsinki, and the protocol was approved by the Institutional Review Board of Ilsan Paik Hospital (approval number: IRB 2019-03-029-001).

\section{Acknowledgments}

I would like to express my gratitude to all those who helped me during the writing of this manuscript.

\section{Conflict of Interest}

The authors declare no conflict of interest.

Submitted: July 10, 2019

Accepted: October 08, 2019

Published: October 152020

\section{References}

[1] Talerman A., Vang R.: "Blaustein's pathology of the female genital tract. Germ cell tumors of the ovary". 2011, 847-907.

[2] Ayhan A., Bukulmez O., Genc C., Karamursel B.S., Ayhan A.: "Mature cystic teratomas of the ovary: case series from one institution over 34 years". Eur. J. Obstet. Gynecol. Reprod. Biol., 2000, 88, 153-157.

[3] Bell M.C., Schmidt-Grimminger D.C., Connor M.G., Alvarez R.D.: "A cervical teratoma with invasive squamous cell carcinoma in an HIV-infected patient: a case report". Gynecol. Oncol., 1996, 60, 475-479.

[4] Lim S.C., Kim Y.S., Lee Y.H., Lee M.S., Lim J.Y.: “ Mature teratoma of the uterine cervix with lymphoid hyperplasia". Pathol. Int., 2003, 53, 327-331.

[5] Wang W.C., Lee M.S., Ko J.L., Lai Y.C.: “Origin of uterine teratoma differs from that of ovarian teratoma: a case of uterine mature cystic teratoma". Int. J. Gynecol. Pathol., 2011, 30, 544-548.

[6] Ansah-Boateng Y., Wells M., Poole D.R.: "Coexistent immature teratoma of the uterus and endometrial adenocarcinoma complicated by gliomatosis peritonei”. Gynecol. Oncol., 1985, 21, 106-110.

[7] Dallenbach-Hellweg G., Wittlinger H.: "Benign solid teratoma of the uterus (author's transl)". Beitr. Pathol., 1976, 158, 307-314.

[8] Khorsandi F., Anabitarte M.: "Immature solid teratoma of the uterine cervix (author's transl)". Geburtshilfe. Frauenheilkd, 1981, 41, 347-349.

[9] Martin E., Scholes J., Richart R.M., Fenoglio C.M.: "Benign cystic teratoma of the uterus". Am. J. Obstet. Gynecol., 1979, 135, 429431.

[10] Sissons M.C., Foria B.: "Benign teratoma of the uterus". J. Obstet. Gynaecol., 2003, 23, 322-323.

[11] Iwanaga S., Ishii H., Nagano H., Shimizu M., Nishida T., Yakushiji M.: "Mature cystic teratoma of the uterine cervix". Asia. Oceania. J. Obstet. Gynaecol., 1990, 16, 363-366.

[12] Stolnicu S., Szekely E., Molnar C., Molnar C.V., Barsan I., D'Alfonso V., et al.: "Mature and immature solid teratomas involving uterine corpus, cervix, and ovary". Int. J. Gynecol. Pathol., 2017, 36, 222-227.

[13] Linder D., Power J.: "Further evidence for post-meiotic origin of teratomas in the human female". Ann. Hum. Genet., 1970, 34, 2130 .

[14] Mann J.R., Gray E.S., Thornton C., Raafat F., Robinson K., Collins G.S., et al.: "Mature and immature extracranial teratomas in children: the UK children's cancer study group experience". J. Clin. Oncol., 2008, 26, 3590-3597.

[15] Gocht A., Löhler J., Scheidel P., Stegner H.E., Saeger W.: "Gliomatosis peritonei combined with mature ovarian teratoma immunohistochemical observations". Pathol. Res. Pract., 1995, 191, 1029-1035.

[16] Calder C.J., Light A.M., Rollason T.P.: "Immature ovarian teratoma with mature peritoneal metastatic deposits showing glial, epithelial, and endometrioid differentiation: a case report and review of the literature". Int. J. Gynecol. Pathol., 1994, 13, 279-282.

[17] Harms D., Janig U., Gobel U.: "Gliomatosis peritonei in childhood and adolescence. Clinicopathological study of 13 cases including immunohistochemical findings". Pathol. Res. Pract., 1989, 184, 422-430.

[18] Bassler R., Theele C., Labach H.: "Nodular and tumorlike gliomatosis peritonei with endometriosis caused by a mature ovarian teratoma". Pathol. Res. Pract., 1982, 175, 392-403.

[19] Truong L.D., Jurco S., McGavran M.H.: "Gliomatosis peritonei. Report of two cases and review of literature". Am. J. Surg. Pathol., 1982, 6, 443-449.

[20] Nielsen S.N., Scheithauer B.W., Gaffey T.A.: “Gliomatosis peritonei". Cancer, 1985, 56, 2499-2503.

[21] Robboy S.J., Scully R.E.: "Ovarian teratoma with glial implants on the peritoneum. An analysis of 12 cases". Hum. Pathol., 1970, 1, 643-653.

[22] Norris H.J., Zirkin H.J., Benson W.L.: "Immature (malignant) teratoma of the ovary: a clinical and pathologic study of 58 cases". Cancer, 1976, 37, 2359-2372.

[23] Ferguson A.W., Katabuchi H., Ronnett B.M., Cho K.R.: "Glial implants in gliomatosis peritonei arise from normal tissue, not from the associated teratoma". Am. J. Pathol., 2001, 159, 51-55.

[24] Kwan M.Y., Kalle W., Lau G.T., Chan J.K.: "Is gliomatosis peritonei derived from the associated ovarian teratoma?". Hum. Pathol., 2004, $35,685-688$.

[25] Albukerk J.N., Berlin M., Palladino V.C., Silverman J.: "Endometriosis in peritoneal gliomatosis". Arch. Pathol. Lab. Med., 1979, 103, 98-99.

[26] Alexander M., Cope N., Renninson J., Hong A., Simpson R.H., 
Hirschowitz L.: "Relationship between endometriosis, endometrioid adenocarcinoma, gliomatosis peritonei, and carcinoid tumor in a patient with recurrent ovarian teratoma". Int. J. Gynecol. Pathol., 2011, 30, 151-157.

[27] Dworak O., Knopfle G., Varchmin-Schultheiss K., Meyer G.: "Gliomatosis peritonei with endometriosis externa". Gynecol. Oncol., 1988, 29, 263-266.

[28] Killeen V.B., Reich H., McGlynn F., Virgilio L.A., Krawitz M.A., Sekel L.: "Pelvic gliomatosis within foci of endometriosis". JSLS, 1997, 1, 267-268.

[29] Kim N.R., Lim S., Jeong J., Cho H.Y.: "Peritoneal and nodal gliomatosis with endometriosis, accompanied with ovarian immature teratoma: a case study and literature review". Korean. J. Pathol., 2013, 47, 587-591.

[30] Muller A.M., Sondgen D., Strunz R., Muller K.M.: "Gliomatosis peritonei: a report of two cases and review of the literature". Eur. $J$. Obstet. Gynecol. Reprod. Biol., 2002, 100, 213-222.

[31] Laux-Biehlmann A., d'Hooghe T., Zollner T.M.: "Menstruation pulls the trigger for inflammation and pain in endometriosis". Trends. Pharmacol. Sci., 2015, 36, 270-276.
[32] Ahn S.H., Monsanto S.P., Miller C., Singh S.S., Thomas R., Tayade C.: "Pathophysiology and immune dysfunction in endometriosis". Biomed. Res. Int., 2015, 2015, 795976

[33] Burney R.O., Giudice L.C.: "Pathogenesis and pathophysiology of endometriosis". Fertil. Steril., 2012, 98, 511-519.

[34] Clement P.B., Young R.H., Oliva E., Sumner H.W., Scully R.E.: "Hyperplastic mesothelial cells within abdominal lymph nodes: mimic of metastatic ovarian carcinoma and serous borderline tumor-a report of two cases associated with ovarian neoplasms." Mod. Pathol., 1996, 9, 879-886.

Corresponding Author:

YOUNG AH KIM, M.D., Ph.D.

Department of Obstetrics and Gynecology, Inje University Ilsan-Paik Hospital, Juwha-ro 170, Ilsandong-gu, Goyang-si, Gyeonggi-do, 10380 (Republic of Korea)

e-mail: camambal@gmail.com 